\title{
A LYAPUNOV-TYPE INEQUALITY FOR A FRACTIONAL DIFFERENTIAL EQUATION UNDER STURM-LIOUVILLE BOUNDARY CONDITIONS
}

\author{
Youyu Wang, Shuilian Liang and ChenXue Xia
}

Abstract. Lyapunov-type inequality is established for a fractional differential equation under Sturm-Liouville boundary conditions. Our results cover many results in the literature.

Mathematics subject classification (2010): 34A08, 34A40, 26D10, 34C10, 33E12.

Keywords and phrases: Lyapunov-type inequality, Riemann-Liouville fractional calculus, Caputo fractional derivative, Sturm-Liouville boundary conditions.

\section{REFERENCES}

[1] R. C. Brown, D. B. Hinton, Lyapunov inequalities and their applications, in Survey on Classical Inequalities, T. M. Rassias, Ed. Kluwer Academic Publishers, Dordrecht, The Netherlands, 2000, 125.

[2] S. Cheng, Lyapunov inequalities for differential and difference equations, Fasc. Math. 23 (1991) $25-41$.

[3] R. A. C. Ferreira, A Lyapunov-type inequality for a fractional boundary value problem, Fract. Calc. Appl. Anal. 16, No. 4 (2013), 978-984.

[4] R. A. C. Ferreira, On a Lyapunov-type inequality and the zeros of a certain Mittag-Leffler function, J. Math. Anal. Appl. 412, No. 2 (2014), 1058-1063.

[5] M. JLELI AND B. SAMET, Lyapunov-type inequalities for a fractional differential equation with mixed boundary conditions, Math. Inequal. Appl. 18, No. 2 (2015), 443-451.

[6] M. JLELI, L. RAGOuB AND B. SAMET, Lyapunov-type inequality for a fractional differential equation under a Robin boundary conditions, J. Func. Spaces. 2015, Article ID 468536, 5 pages.

[7] A. A. Kilbas, H. M. SRivastava And J. J. Trujillo, Theory and applications of fractional differential equations, North-Holland Mathematics Studies 204 Elsevier, Amsterdam, The Netherlands, 2006.

[8] A. M. Lyapunov, Probleme général de la stabilité du mouvement, (French Translation of a Russian paper dated 1893), Ann. Fac. Sci. Univ. Toulouse 2 (1907), 27-247 (Reprinted as Ann. Math. Studies, No. 17, Princeton Univ. Press, Princeton, NJ, USA, 1947).

[9] A. Tiryaki, Recent development of Lyapunov-type inequalities, Adv. Dyn. Syst. Appl., 5 No. 2 (2010), 231-248. 